\title{
APROXIMACIÓN CRÍTICA ENTRE LAS JURISDICCIONES DEL CIVIL LAW Y DEL COMMON LAW Y LA NECESIDAD DE RESPETO A LOS PRECEDENTES*
}

Luiz Guilherme Marinoni***

\begin{abstract}
RESUMEN:
El presente trabajo pretende demostrar, mediante un método históricocrítico, la aproximación entre las jurisdicciones del civil law y del common law, y en tal dimensión la necesidad de rendirse respeto a los precedentes en el civil law.
\end{abstract}

Palabras Clave: Civil law, common law, precedentes vinculantes, stare decisis.

\begin{abstract}
:
This paper aims to demonstrate through a critical and historical approach the approximation between common law and the civil law, and, as a direct consequence, the need to give appropriate respect to precedents in the civil law.
\end{abstract}

Key words: Civil law, common law, stare decisis, binding precedent.

\section{INTRODUCCIÓN}

El civil law y el common law surgieron en circunstancias políticas y culturales completamente distintas lo que naturalmente llevó a la formación de tradiciones jurídicas diferentes, definidas por institutos y conceptos propios a cada uno de los sistemas.

* El artículo es una versión inédita de otro publicado en Brasil. Traducción de Christian Delgado Suárez. Maestro en Derecho Procesal de la Universidad Federal del Paraná, Brasil.

*:* Profesor titular de la Universidad Federal del Paraná (Brasil). Post Doctorado de la Università degli Studi di Milano. Visiting Scholar en Columbia University. Director del Instituto de Proceso Comparado. Abogado. 
El civil Law carga, a partir de las banderas de la Revolución Francesa, dogmas que todavía sirven para negar conceptos e institutos que, aunque no se adhieren a su teoría y tradición, se muestran indispensables delante de la práctica y de la realidad de países que se formaron a partir de la doctrina de la separación estricta entre los poderes y de la mera declaración judicial de la ley.

No obstante las transformaciones que operaron en el Civil Law -inclusive en las concepciones de derecho y de jurisdicción, marcadamente en virtud del impacto del constitucionalismo- existe notoria resistencia, por no decir, indiferencia, a institutos del common law de gran importancia al perfeccionamiento de nuestro derecho, como es el caso del respeto a los precedentes.

Este texto pretende demostrar, mediante un método histórico-crítico, la aproximación entre las jurisdicciones del civil law y del common law, y en tal dimensión, la necesidad de rendirse respeto a los precedentes en el civil law. En un sistema que, al expurgar los dogmas, se depara con el hecho inapartable de que la ley es interpretada de diversos modos, no hay otra alternativa para preservar la igualdad ante la ley y la seguridad jurídica, elementos indispensables en un Estado de Derecho.

\section{EL COMMON LAW: LAS TEORÍAS DECLARATORIA Y CONSTITUTIVA DE LA JURISDICCIÓN}

En el common law se discutió intensamente sobre el significado de la decisión judicial o, propiamente, sobre el significado de la función jurisdiccional. Se deseaba esclarecer si la decisión judicial creaba el derecho o solamente lo declaraba y, bien fue por eso que se intuyó que se estaba discutiendo una teoría de la jurisdicción ${ }^{1}$.

Inicialmente, se sustentó en Inglaterra la tesis de que el juez sólo declaraba el derecho, siendo uno de sus principales defensores William Blackstone ${ }^{2}$. En su entender, existiría la lex non scripta -el derecho no escrito en el common Law- y la ley escrita -el derecho escrito o un statute law-. El common law propiamente dicho reflejaría tantas costumbres generales ("costumbres establecidas" y "reglas y máximas establecidas") ${ }^{3}$, como costumbres particulares de algunas partes del reino, junto a aquellas observadas sólo en algunas cortes y jurisdicciones ${ }^{4}$.

La suposición de que el common law consiste en las costumbres generales hace apreciar a la teoría declaratoria en otra perspectiva, esto es, la propia teoría declaratoria bajo disfraz. Partiéndose de la idea de que el common law está en las

1 WESLEY-SMITH, Peter. "Theories of adjudication and the status of stare decisis". En: Goldstein, L. (ed.). Precedent in law. Oxford: Clarendon Press, 1987, p. 73 y ss.

2 BLACKSTONE, William. Commentaries on the law of England (facsimile de la primera edición, de 1765). Chicago: The University of Chicago Press, 1979. vol. 1, p. 69.

$3 \quad$ Ibidem, p. 68.

4 CROSS, Rupert; HARRIS, J. W. Precedent in English law. Oxford: Clarendon Press, 1991. p. 168. 
costumbres generales observadas entre los Englishmen, el juez no la crea, sino simplemente la declara. De ahí la conclusión de Blackstone de que las decisiones de las Cortes constituían la demostración de lo que el common law es ${ }^{5}$.

No obstante, la naturaleza declaratoria también era resaltada cuando la decisión se basaba en un anterior precedente judicial. Si los precedentes se destinan a desarrollar el common law, decisiones iguales sobre un punto de derecho significarían, igualmente, common law. Para la teoría en análisis, el juez estaba limitado a declarar el derecho fijado en los precedentes. Su autoridad no le daba poder para crear un nuevo derecho, pero apenas para mantener y declarar un derecho ya conocido.

Jeremy Bentham y John Austin condenaron de manera contundente la teoría declaratoria. Bentham la igualó al método adoptado para el entrenamiento de perros -llegó a calificarla, literalmente, de $\operatorname{dog}$-la $w^{6}$ - al paso que Austin la acusó de ficción infantil ${ }^{7}$. Para este autor, los jueces tendrían la noción ingenua de que el common law no sería producido por ellos, pero se constituiría en algo milagroso, hecho por nadie, existente desde siempre y para la eternidad, meramente declarado de tiempo en tiempo. El common law, en la concepción de la teoría positivista, existía por ser establecido por los jueces que poseían law making authority, siendo el derecho, entonces, producto de la voluntad de los magistrados: no algo meramente descubierto, sino, creado ${ }^{8}$.

Cualquiera que sea la justificativa teórica empleada con la finalidad de concluir que el juez posee autoridad para crear derecho, existe, antes, la necesidad de conocer la realidad en que el Estado inglés se formó al admitir la law making authority. Aquí no importa saber si la decisión declara o crea derecho, pero sí considerar el motivo por el cual el common law admitió, al revés de lo que sucedió en el civil law, que el juez tenía autoridad para crear derecho.

No obstante, la naturaleza declaratoria o constitutiva de la decisión judicial podría tener relevancia para la cuestión del respeto obligatorio a los precedentes o, en otras palabras, para el stare decisis, mientras sea tomado en su acepción corriente en el derecho estadounidense. Se afirmó que, si el precedente representa apenas una evidencia del derecho, ningún juez podría ser absolutamente obligado a seguirlo, toda vez que el juez siempre tendría el poder de declarar contrariamente

BLACKSTONE, William. Op. cit., p. 86.

6 BENTHAM, Jeremy. Truth versus Ashhurst; or law as it is, contrasted with what it is said to be. The works of Jeremy Bentham (published under the superintendence of his executor, John Bowring). Edinburgh: William Tait, 1843. vol. 5, pp. 231-238.

7 AUSTIN, John. Lectures on jurisprudence, or the philosophy of positive law. 5. ed. rev. London: John Murray, 1911. vol. 2, p. 634.

8 "The common law, said the positivists, existed (if it existed at all) because it was laid down by judges who possessed law-making authority. Law was the product of judicial will. It was not discovered but created". (WESLEY-SMITH, Peter. Op. cit., p. 74). 
al precedente o incluso a su overruling (revocación) ${ }^{9}$. En esta línea, el stare decisis (respeto obligatorio a los precedentes) exigiría, como antecedente lógico, la creación judicial del derecho.

De la relación entre la naturaleza constitutiva de la decisión judicial y el stare decisis se formaron tres mitos: i) el common law no existe sin el stare decisis; ii) el juez del common law, por crear derecho, realiza una función absolutamente diversa de aquella que realiza su colega del civil law; y iii) el stare decisis es incompatible con el civil law.

Sin embargo, la verdad es que la creación judicial del derecho no constituye un presupuesto para el stare decisis. El respeto al pasado es trazo peculiar a la teoría declaratoria, con la diferencia de que el precedente, en vez de constituir, declara el derecho consuetudinario o representa el propio desarrollo de las costumbres generales, o sea, el common law. Así, aunque se admitiese que la función judicial fuese meramente declaratoria, nada podría indicar que el juez estuviese menos dispuesto a respetar el pasado. Por otro lado, incluso que se aceptase la creación judicial del derecho, nada podría asegurar que el juez estaría obligado a respetar los precedentes. Déjese en claro, desde luego, que tanto la teoría declaratoria, cuanto la constitutiva, fueron obligadas a admitir la revocación del precedente cuyo contenido no pudiese ser presentado nuevamente sin generar injusticia en el caso concreto.

Neil MacCormick, en el trabajo sugestivamente titulado Can stare decisis be abolished? ${ }^{10}$, luego de alegar que Bentham y Austin demostraron el "disparate de la teoría declaratoria del precedente", y afirmar que sus doctrinas pasaron a hacer parte de la "herencia [bag-and-baggage] intelectual del derecho", realiza una interesante construcción ${ }^{11}$. El jurista escocés advierte que, como los jueces estaban sumergidos en la cultura jurídica que evidenciaba el colapso de la teoría declaratoria, los magistrados no más podrían esconderse atrás de esta teoría en caso deseasen revocar los precedentes. De acuerdo con MacCormick, el juez tendría que legislar abiertamente para seguir a Austin. Como la doctrina austiniana sustenta que el juez crea el derecho, su aceptación exigiría que los jueces también admitiesen que realmente podrían legislar, inclusive al revocar los precedentes.

Todavía, relata MacCormick que la invitación de Austin no fue aceptada. Es que los jueces se sentían cómodos al declarar y no querían asumir la responsabilidad de crear el derecho y de revocar los precedentes. Así, es realmente posible decir que los jueces tuvieron buenas razones para mantenerse presos a la teoría declaratoria, permitiéndole una larga vida, especialmente por librarse del peso de las decisiones retroactivas que podrían ser consideradas como no democráticas ${ }^{12}$.

9 CROSS, Rupert; HARRIS, J. W. Op. cit., p. 30.

10 MACCORMICK, Neil. Can stare decisis be abolished? p. 197 y ss.

11 Ibídem, p. 204.

12 WESLEY-SMITH, Peter. Op. cit., p. 76. 
Nótese que la argumentación de MacCormick y la propia doctrina de Austin no sólo sustentaron la impropiedad de la naturaleza declaratoria de la decisión judicial, habiendo también subrayado que el juez, al revocar el precedente, siempre estaría creando el derecho. Para Austin, la teoría declaratoria entraría en contradicción con la revocación del precedente, una vez que, si la primera Corte cometió un error, el juez que se encuentra con el caso en las manos tendría que legislar o hacer algo bien diferente de lo que declarar el derecho contenido en el precedente ${ }^{13}$.

Reafírmese que no interesa, aquí, saber cuál de esas teorías estaba en lo correcto. Los propios partidarios de la teoría de que el juez crea derecho, al considerar la necesidad de la revocación del precedente, anunciaron que, en este caso, ocurriría un remaking. No importa si el juez reconstruye el derecho o declara el error de la primitiva declaración del derecho cuando una u otra explicación sirve para justificar la revocación de precedentes. Ahora, al justificar tal revocación, ambas teorías estaban conscientes del deber judicial del respeto a los precedentes.

Lo que releva muchísimo, delante de la argumentación de MacCormick, es que los propios jueces llegaron a la conclusión de que la ruptura con los precedentes significaría legislar y, por eso, se mantuvieron adscritos a los precedentes, dando una bella demostración concreta, por qué es perceptible en la historia de los precedentes, de que la aceptación de la naturaleza declaratoria de la decisión judicial no es incompatible con el stare decisis.

Déjese bien en claro, no obstante, que no se está sustentando que la base del stare decisis, en Inglaterra, sólo podría estar en la teoría declaratoria, o que esta teoría justifica de manera perfecta y adecuada el stare decisis. En verdad, ni la teoría declaratoria, tampoco la constitutiva o positivista, son capaces de coherentemente justificar el stare decisis en su estado absoluto o en su conformación pura ${ }^{14}$.

Para minar la teoría declaratoria, sería posible decir que el juez es obligado a respetar el derecho y no la declaración judicial de lo que es el derecho. En otras palabras, si el precedente no es derecho, pero sí la declaración de un juez acerca del derecho, no habría cómo imponer a los demás jueces el respeto al precedente. Esto se tornaría más fácil al suponerse que el juez puede crear derecho ${ }^{15}$.

13 Neil Duxbury, al tratar el mencionado texto de MacCormick y, así también del impacto de la doctrina de Austin sobre la práctica de los jueces, escribe: "If judges have a duty to find and declare the law themselves, they can only be bound to follow the ruling of another court where that ruling is itself a correct declaration of the law. If the earlier court made a mistake, judges deciding the case in hand must declare the law by doing something other than following the precedent". (DUXBURY, Neil. Op. cit., p. 39).

14 "The result is that whichever theory [declaratory or positivist] of their function is adopted by judges it is incompatible with stare decisis" (WESLEY-SMITH, Peter. Op. cit., p. 87).

15 "When a judge is recognized, however, as able to make law, the notion of vertical stare decisisof a court being bound by decisions of courts above it in the hierarchy -is perfectly rational" (Ibídem, p. 81). 
La noción de que el juez puede crear derecho sólo justificaría el llamado efecto vertical del stare decisis, una vez que el precedente apenas obligaría a los jueces y Cortes inferiores. O sea, la teoría constitutiva, en la dimensión de la discusión en que fue insertada delante del stare decisis inglés, no sería capaz de obligar a la propia Corte que firmó el precedente. Esto quiere decir que la idea del juez dotado de making law authority no sería capaz de dar fundamento al stare decisis exactamente en el local en que él es más importante.

Si los precedentes pueden ser revocados, es evidente que el respeto debido a ellos depende de la fuerza de sus razones. Por lo tanto, no es porque la decisión es llamada de declaración judicial y no de derecho por la que ella perderá autoridad y dejará de merecer deferencia. De otra parte, si el respeto a los precedentes depende de que estos sean concebidos como derecho, nada impediría que una decisión judicial, vista entonces como derecho, afirmase que los propios jueces de la Corte Superior están, a partir de determinado instante, sometidos a sus propios precedentes, o que el legislativo editase una ley diciendo que las Cortes deben respetar sus precedentes y los de las Cortes superiores. En relación al funcionamiento y a la eficiencia del stare decisis, la diferencia residiría sólo en el aspecto formal. En un caso la obligatoriedad advendría de un precedente: en el otro, la obligatoriedad devendría de la ley.

Nótese, además, que el stare decisis solamente se solidificó en Inglaterra al final del siglo XIX, mucho tiempo después de la aparición de las doctrinas de Bentham y de Austin ${ }^{16}$. London Trainway vs. London County Council, decidido en 1898, constituyó la cumbre de una evolución en dirección a la vinculación de la House of $\operatorname{Lords}^{17}$ a sus propias decisiones, pues el concepto de rules of precedent y la idea de vinculación (binding effect) fueron consolidados en el periodo entre 1863 y 1900 . De hecho, cuando en este caso fue clara y objetivamente colocada la cuestión relativa a la posibilidad de la House considerar argumentos para contrariar sus decisiones, no hubo hesitación en decidirse que esto no podría ocurriri ${ }^{18}$. Esto es, la vinculación

16 DUXBURY, Neil. Op. cit., p. 114 y ss.

17 Recientemente, la House of Lords, fue "sustituida" por la Supreme Court of the United Kingdom, que asumió sus funciones judiciales. La Supreme Court of the United Kingdom fue creada por el Acto de Reforma Constitucional del 2005 (Part 3, Constitutional Reform Act 2005), habiendo iniciado sus actividades el 1 de octubre del 2009. Se argumentó, en defensa de la creación de la Supreme Court que la histórica aproximación de la House of Lords con el Parlamento y con el Ejecutivo podría perjudicar el Reino Unido delante de la Convención Europea de Derechos Humanos. Se temía que las decisiones de la House of Lords pudiesen ser mal recibidas (como si no constituyesen fair trial) por la Corte Europea de Derechos Humanos.

18 "Cuando en 1898, en London Tramways Co. V. London County Council, el problema fue claramente colocado sobre la posibilidad de la House escuchar argumentos solicitando que reconsiderase una decisión anterior, ella no hesitó en decir que no podría" (EVANS, Jim. Precedent in the nineteenth century. En: GOLDSTEIN, L. (ed.) Precedent in law. Oxford: Clarendon Press, 1987. p. 58). 
horizontal, en la House of Lords, es deudora de un precedente con valor de rule of precedent (de regla concerniente a la eficacia de los precedentes) y no al derecho sustancial.

Conclúyase, así, en este tópico, que tanto la teoría declaratoria como la teoría constitutiva se adaptaron a un sistema de respeto obligatorio a los precedentes.

\section{COMMON LAW Y STARE DECISIS}

No hay que confundir common law con stare decisis. Ahora, el common law, comprendido como costumbres generales que determinaban el comportamiento de los Englishmen, existió, por varios siglos, sin stare decisis y rule of precedent.

Como escribe Simpson, cualquier identificación entre el sistema del common law y la doctrina de los precedentes, cualquier intento de explicar la naturaleza del common law en términos de stare decisis será insatisfactoria, una vez que la elaboración de reglas y principios regulando el uso de los precedentes y la determinación y aceptación de su autoridad son relativamente reciente, para no hablarse de la noción de precedentes vinculantes (binding precedents), que es más reciente aún. Además del common law haber nacido siglos antes de alguien preocuparse con tales cuestiones, éste funcionó muy bien como sistema de derecho sin los fundamentos y conceptos propios de la teoría de los precedentes, como, por ejemplo, el concepto de ratio decidendi $i^{19}$.

El realce de la distinción entre stare decisis y common law, además de ser necesaria para apartar una vulgar confusión, se centra en la preocupación en sustentar que el sistema de precedentes puede constituir parte de un sistema de civil law. En efecto, el stare decisis constituye apenas un elemento del moderno common law, que también no se confunde con el common law de tiempos inmemorables o con las costumbres generales, de naturaleza secular, que dirigían el comportamiento de los Englishmen. Es imprescindible tener en mente que, aunque el derecho jurisprudencial contemporáneo tenga configuración distinta y más amplia de aquel de la antigüedad, y que el stare decisis sea algo que hace parte de la modernidad, no hay cómo identificar el common law de los días de hoy con el stare decisis ${ }^{20}$. Así, la circunstancia de el common law haber iniciado su existencia antes de hablarse en stare decisis no es la única distinción entre ambos.

Pero, incluso siendo correcto que el stare decisis no es necesario para la existencia del sistema de derecho material ni para el funcionamiento del sistema de

19 Véase: SIMPSON, A. W. B. The Common Law and legal theory. In: Horder, Jeremy (ed.). Oxford essays in jurisprudence. Oxford: Clarendon Press, 1973. p. 77).

20 Véase: GAMBARO, Antonio. Civil Law e Common Law: evoluzione e metodi di confronto. Rivista Trimestrale di Diritto e Procedura Civile, Numero Speciale: Due iceberg a confronto: le derive di Common Law e Civil Law, 2009, n. 4, p. 12. 
distribución de justicia, alguien podría decir que éste es indispensable en el common law bajo el argumento de que ahí las decisiones judiciales establecen el derecho no edificado por el legislativo.

\section{4. ¿CREACIÓN JUDICIAL DEL DERECHO EN VIRTUD DE LA OMISIÓN DEL LEGISLATIVO?}

No hay cómo negar la importancia que el stare decisis tuvo para el desarrollo del common law en su faceta moderna, tampoco olvidar que los precedentes -al lado de la ley y de las costumbres- constituyen fuente de derecho en este sistema.

El magistrado inglés tuvo fundamental importancia en la consolidación del common law -de ahí que se refiera al judge make law-. El poder del juez era el de afirmar el common law, el cual se sobreponía al legislativo, que, por eso, debería actuar de modo a complementarlo.

A propósito, en la tradición del common law inglés, el Parlamento consideraba las decisiones proferidas por las Cortes en los casos concretos para, a partir de ellas, precisar y delinear la ley derivada de la voluntad común. Resulta interesante percibir que exactamente ahí surge una primitiva noción de due process of law, visto como el camino a ser seguido para la elaboración de la ley anclada en las costumbres ${ }^{21}$.

En este sistema, el legislativo no se opuso al judicial, llegando, en realidad, a confundirse con él ${ }^{22}$. En Inglaterra, el juez estuvo al lado del Parlamento en la lucha contra el arbitrio del monarca, reivindicando la tutela de los derechos y de las libertades del ciudadano. Por eso mismo, al contrario de lo que ocurrió de cara a la Revolución Francesa, no hubo clima para desconfiar del poder judicial o para suponer que los jueces se posicionarían a favor del rey o del absolutismo.

En el derecho inglés no hubo necesidad de elaborar el dogma de la aplicación estricta de la ley o de imaginar que el juez apenas podría actuar mediante la mera descripción de los términos de la ley. El common law no necesitó negar la naturaleza de las cosas o crear una prohibición que solamente puede ser comprendida como una de esas reglas que adviene de las utopías de una revolución. El juez inglés no sólo interpretaba la ley, como también extraía derechos y deberes a partir del common Law. Pero -es importante resaltar- estaba sometido al common Law; siempre actuaba a la luz y a partir de un derecho.

${ }_{21}$ Véase: GROTE, Rainer. Rule of law, etat de droit and Rechtsstaat - The origins of the different national traditions and the prospects for their convergence in the light of recent constitutional developments. Disponible en: www.eur.nl/frg/iacl/papers/grote.html [Consultado el 15/ 04/ 2009, p. 3].

22 Véase: ARGÜELLES, Juan Ramón de Páramo; ROIG, Francisco Javier Ansuátegui. "Los derechos en la Revolución Inglesa". En: Fernández, Eusebio; Peces-Barba, Gregorio (org.). Historia de los derechos fundamentales - Transito a la modernidad: siglos XVI y XVII. Madrid: Dykinson, 2003. tomo I, p. 770). 
De cualquier forma, si es que en el derecho inglés primitivo había baja producción de leyes, eso no ocurre en el common law contemporáneo. La suposición de que, en Estados Unidos, la producción legislativa del derecho es baja, lo que impone su creación por los jueces, no sólo es falsa (he aquí, calcada, a lo que parece, en suposiciones partidarias infundadas), como produce engaños en términos de derecho comparado. Es probable que un estado típico de los Estados Unidos tenga tanta legislación cuanto un país europeo o latino americano, la cual debe ser obviamente aplicada e interpretada por los jueces ${ }^{23}$.

Nótese, por lo tanto, que, aunque se pueda admitir que el common law, en su origen inglés, era apenas complementado por el legislativo, o que la actuación de este poder era en este aspecto poco intensa, la existencia de la ley no se opone al common law, o, más importante y mucho más fácil de ser visualizado; la profusión de las leyes no excluye la necesidad de un sistema de precedentes.

En el common law, la autoridad de la ley es superior a aquella de las decisiones judiciales ${ }^{24}$, y no al contrario, lo que autoriza decir que la cantidad de leyes y su grado de autoridad constituyen criterios absolutamente inútiles para distinguir este sistema del civil law.

\section{5. ¿CREACIÓN JUdICIAL DEL DERECHO COMO CONSECUENCIA DEL STARE DECISIS?}

Cuando se dice que el juez del common law crea derecho, no se está pensando que su decisión tenga la misma fuerza y calidad que la del producto elaborado por el legislativo, esto es, de la ley. La decisión no se equipara a la ley por el hecho de tener fuerza obligatoria para los demás jueces.

23 MERRYMAN; John Henry; PÉREZ-PERDOMO, Rogelio. The Civil Law tradition: an introduction to the legal systems of Europe and Latin America. Stanford: Stanford University Press, 2007. p. 27 y ss.

24 Es lo que se puede observar, por ejemplo, de la Supremacy Clause (Cláusula de Supremacía), constante del artículo VI, cláusula 2, de la Constitución de los Estados Unidos de América, según la cual la Constitución, las Leyes Federales y los Tratados realizados bajo la autoridad de aquella nación, representan la "Ley Suprema del País", estando los jueces de todos los Estados a ellas subordinadas, restando apartadas cualesquiera determinaciones en contrario, constante en la Constitución o en las Leyes Estatales. Pierde efecto, igualmente, conforme la anotación de Caleb Nelson, cualquier interpretación judicial contraria a tales normas (NELSON, Caleb. Stare decisis and demonstrably erroneous precedents. Virginia Law Review, vol. 87, marzo 2001, pp. 01-79). No se puede negar, todavía, que ni inclusive aquello que Maltz menciona como supremacy of the statutes (supremacía de los derechos legislados) es capaz de estancar, por completo, la doctrina constante en los precedentes anteriores a la legislación. Ella continúa, sí, ejerciendo influencia, aunque como "uno de los varios factores que influencian la interpretación de la norma judicial de la norma específica". (MALTZ, Earl. "The nature of precedent”. North Carolina Law Review, vol. 66, pp. 367-392, enero 1988). 
No obstante, sería posible argumentar que la decisión, por tener fuerza obligatoria, constituye derecho. El common law considera el precedente como fuente de derecho ${ }^{25}$. Nótese, pero, que cuando un precedente interpreta la ley o la Constitución, como ocurre especialmente en los Estados Unidos, hay, evidentemente, derecho pre-existente con fuerza normativa, de modo que sería absurdo pensar que el juez, en este caso, crea un derecho nuevo. En verdad, también en el caso en que había sólo costumbre, existía derecho pre-existente, el derecho consuetudinario.

La circunstancia del precedente admitido como fuente de derecho está muy lejos de constituir un indicio de que el juez cree el derecho a partir de su propia voluntad. En esta perspectiva, la fuerza obligatoria del precedente, o la admisión del precedente como fuente de derecho, no significa que el judicial tiene poder para crear el derecho.

\section{VERDADERO SIGNIFICADO DEL LAW-MAKING AUTHORITY}

Lo que permite decir que el juez del common law crea el derecho es la comparación de su papel con el del juez de la tradición del civil law, cuya función se limitaba a la mecánica aplicación de la ley. En este sistema, cuando se decía que al juez cabía apenas expresar las palabras dictadas por el legislador, el derecho era concebido únicamente como ley. La tarea del Poder Judicial se resumía a la aplicación de las normas generales.

El juez inglés no sólo tuvo espacio para densificar el common law, como también oportunidad de, a partir de éste, controlar la legitimidad de los actos estatales. En ese sentido, Edward Coke -cuyo papel fue muy importante, aunque en nivel doctrinario, para la contención del arbitrio del rey- decidió en el célebre caso Bonham, alrededor de los años 1610, que las leyes están sometidas a un derecho superior, el common law y, cuando eso no ocurriese, vale decir, cuando no se respetase este derecho, serían nulas y destituidas de eficacia. Dijo Coke, en esta ocasión que, en muchos casos, el common law controlará los actos del Parlamento y algunas veces los juzgará absolutamente nulos: puesto que, cuando un acto del Parlamento fuere contrario a algún derecho o razón común o repugnante, o imposible de ser aplicado, el common law irá a controlarlos y juzgarlos como si fuesen nulos ${ }^{26}$.

25 Ver: ALGERO, Mary G. "The sources of law and the value of precedent: a comparative and empirical study of a civil law state in a common law nation", Louisiana Law Review, vol. 65, 2005, pp. 775-785; CONNORS, Jordan Wilder. Treating like subdecisions alike: the scope of stare decisis as applied to judicial methodology. Columbia Law Review, vol. 108, n. 3, pp. 681-715, abril 2008.

26 "Y parece que en nuestros libros, en muchos casos, el common law controlará los actos del Parlamento y algunas veces los juzgará absolutamente nulos: visto que, cuando un acto del Parlamento fuere contario a algún derecho o razón común o repugnante o imposible de ser aplicado, el common law irá a controlarlo y juzgarlo como si fuere nulo" (GROTE, Rainer. Op. cit., p. 2). 
Esclarézcase que, a pesar de que la decisión de Coke está vinculada a la teoría declaratoria de la jurisdicción y no a la teoría que afirma la law-making authority -la teoría constitutiva-, su remembranza es pertinente para demostrar que el juez del Common law realizaba una especie de control de los actos del Parlamento. Se ve, en la decisión proferida en el caso Bonham, el primero germen del control de constitucionalidad de las leyes y, así, es posible de ahí también extraer la noción de que el poder judicial en el common law primitivo era ejercido mediante una lógica semejante a la que dirige la actuación del juez sometido a la Constitución y a los derechos fundamentales ${ }^{27}$.

La evolución del civil law, particularmente en virtud del impacto del constitucionalismo, dio a los jueces un poder similar a aquel del juez inglés sometido al common law y, claramente al poder del juez americano, dotado de poder de controlar la ley a partir de la Constitución. En el instante en que la ley pierde la supremacía sometiéndose a la Constitución, se transforma no sólo el concepto de derecho, sino, igualmente el significado de jurisdicción. El juez deja de ser un siervo de la ley y asume el deber de dimensionarla en la medida de los derechos positivados en la Constitución. Si el juez puede negar la validez de la ley de cara a la Constitución o incluso instituyese una regla imprescindible para la realización del derecho fundamental, su papel no es más aquel concebido por juristas y procesalistas de épocas distantes. A propósito, el juez brasilero, hoy, tiene poder "creativo" mayor que el juez del common law, una vez que contrario que aquel, no presta el adecuado respeto a los precedentes.

En efecto, si alguien preguntara a un teórico del common law al respecto de la naturaleza de la función del juez que no aplica la ley por reputarla inconstitucional, que se vale de la técnica de interpretación conforme la Constitución o que suple la omisión de un regla procesal que debería haber sido establecida en virtud de un derecho fundamental de naturaleza procesal, ciertamente se sorprenderá.

Cuando algunos países de Europa Continental adoptaron "tribunales constitucionales" -entre ellos, Austria, Alemania, Italia y España- se objetivó reafirmar el principio de separación de poderes, dejándose claro que el control de constitucionalidad no sería realizado por los jueces ordinarios pero sí por un cuerpo formado por miembros especialmente seleccionados. A propósito, se llegó a acusar de equivocada la denominación "tribunales" conferida a tales órganos, bien como inapropiado llamar de jueces a los miembros de esa corte. Por detrás de eso, estaba la idea de que el control de constitucionalidad de la ley no era una actividad jurisdiccional, o mejor, que declarar la inconstitucionalidad de la ley sería una forma de crear el derecho ${ }^{28}$.

\footnotetext{
$27 \quad$ Ver ARGÜELLES, Juan Ramón de Páramo; Roig, Francisco Javier Ansuátegui. Op. cit., p. 774.

MERRYMAN, John Henry; PÉREZ-PERDOMO, Rogelio. Op. cit., pp. 37-38.
} 
No obstante, la concepción dogmática de que el derecho se restringe al producto del legislativo, anclada en la ideología de la Revolución Francesa y en el dogma de la estricta separación de poderes ${ }^{29}$, no sobrevivió a los hechos históricos, a la conformación diversificada de los sistemas jurídicos de los varios países del civil law y, sobretodo, al adviento del constitucionalismo. Anótese que John Henry Merryman, uno de los mayores comparatistas estadounidenses, admitiendo que el constitucionalismo hizo surgir una nueva fuente de derecho en el civil law, advierte que, en la aceptación de que el juez puede decidir sobre la invalidez de una ley por estar en conflicto con la Constitución, se quiebra el dogma de la separación estricta entre el Poder Legislativo y el Poder Judicial y, de esta forma, se abre oportunidad para decir que el juez del civil law también crea derecho ${ }^{30}$.

En los días que corren, la diferencia entre el magistrado del common law y el del civil law no está en la elasticidad de sus elaboraciones o interpretaciones, sino, en la importancia que ellos asumen en cada uno de los sistemas y, por consecuencia, en el respeto que les es debido. Y no es equivocado decir que uno de los principales responsables por el trazo fuerte de la figura del juez del common law es justamente el sistema de precedentes.

\section{De LA "SUPREMACY OF THE ENGLiSH PARLIAMENT" AL "JUDICIAL REVIEW" ESTADOUNIDENSE}

En los ítems anteriores, se comparó el juez del civil law marcado por el constitucionalismo con el juez americano -que posee poder para controlar la constitucionalidad de la ley- y, de forma tímida y cautelosa, con el juez inglés, que, en las palabras de Coke, podía controlar la ley a partir del common law. Cabe evidenciar, ahora, que el control de los actos del legislador tiene historias y valores distintos en Inglaterra y en los Estados Unidos.

En este contexto, importa rememorar la disputa entre las teorías declaratoria y constitutiva de la jurisdicción. La teoría declaratoria no sólo intentó demostrar que la función del juez es la revelar el derecho -por ser éste, en las palabras de Blackstone, un "oráculo vivo"- ${ }^{31}$ sino, igualmente, tuvo el propósito de permitir al poder judicial declarar o afirmar el common law contra el soberano y contra el Parlamento, con la intención de viabilizar de esta forma, una especie de control judicial de los actos estatales.

29 No obstante las revolución francesa y americana tengan en sus raíces la separación de poderes elaborada por Montesquieu, el papel de los jueces en los dos países tomó rumbos completamente distintos, al punto de los "padres de la Revolución Francesa", entre ellos Robespierre y Le Chaplier, haber considerado que tan sólo la ley escrita sería válida y que "el judge-make law era la más detestable de las instituciones, debiendo ser destruido" (WACHTLER, Sol. "Judicial lawmaking". New York University Law Review, vol. 65, 1990, pp. 1-22).

30 MERRYMAN, John Henry; PÉREZ-PERDOMO, Rogelio. Op. cit., p. 25.

31 BLACKSTONE, William. Op. cit., pp. 68-69. 
La doctrina de Coke afirmó que el common law se sobreponía al soberano y al legislativo ${ }^{32}$, de modo que la teoría de que el juez sólo declaraba el derecho también tuvo una importante función legitimadora al admitir el control de los actos del Parlamento y del monarca.

Con la Revolución Gloriosa de 1688, es establecido el instituto de la supremacy of the parliament. La doctrina de la supremacía del legislativo sirvió para que el Reino inglés controlase los actos de sus colonias y, después, tuvo el efecto de hacer surgir, en los Estados Unidos, un principio que, en una visión estricta del Civil Law, podría ser tomado como su opuesto, esto es, el de la supremacy of the judiciary.

Las colonias inglesas, regidas por Cartas, fueron prohibidas de realizar actos contrarios al derecho inglés. La supremacía del parlamento inglés se imponía, mediante las Cartas, de forma a no permitir la aplicación judicial de leyes coloniales contrastantes.

Con el control de la legislación de la colonia, surgen las semillas del judicial review. Esto quiere decir que, en el momento en que el principio de la supremacía del parlamento es transportado para la colonia, surge el control judicial de sus actos y, de esta forma, el brote del principio de la supremacía del poder judicial. En este sentido, el principio inglés de la supremacía del parlamento, en lugar de obstaculizar, en realidad colaboró para el desarrollo del control judicial de la constitucionalidad de las leyes en los Estados Unidos.

Anótese, sin embargo, que la ideología de la imprescindibilidad de la imposición de límites al legislativo mediante una ley mayor puede ser vista cuando los colonizadores de América del Norte -que no tenían representantes en el parlamento inglés- se rebelaron contra los tributos exigidos por el gobierno de la metrópolis mediante la alegación de que cualquier acto del Parlamento contrario a la equidad natural sería nulo ${ }^{33}$.

Con la independencia de las colonias americanas en 1776, las Cartas fueron sustituidas por las nuevas Constituciones y, como anteriormente los jueces ya tenían la consciencia y la práctica de decretar la nulidad de las leyes que violasen las Cartas y la legislación del Reino inglés, se tornó prácticamente "natural" controlar las leyes que contrariasen las Constituciones de los Estados que acababan de adquirir la independencia ${ }^{34}$.

Mauro Cappelletti, en su célebre Il controllo giudiziario di costituzionalità delle leggi nel diritto comparato, alega que la doctrina de Coke y, específicamente, la sumisión del Parlamento al Common law desaparecieron con la Revolución de 1688 y con la institución del principio de la supremacy of the parliament. Entretanto, esta

32 COKE, Edward. Seventh reports - Calvin's case. London: Thomas and Fraser, 1826, vol. 4, p. 6. Cf. POSTEMA, Gerald J. "Some roots of our notion of precedent". En: GOLDSTEIN, L. Precedent in law. Oxford: Clarendon Press, 1987. pp. 17-18.

33 GROTE, Rainer. Op. cit., p. 3.

34 CAPPELLETTI, Mauro. Il controllo giudiziario di costituzionalità..., p. 41 y ss. 
afirmación no parece correcta, particularmente para los efectos que Cappelletti intenta extraer de esta "transformación" -que, bien vistas las cosas, no ocurrió-. He aquí lo que dice Cappelletti: "Tal doctrina (la de Coke) fue abandonada en Inglaterra con la Revolución de 1688, cuando entonces fue proclamada la doctrina contraria -todavía hoy respetada en aquel país- de la supremacía del parlamento. Sin embargo, de la doctrina de Coke restaron los frutos, al menos en los Estados Unidos, y estoy refiriéndome, como es obvio, a los frutos que hoy son llamados de judicial review y supremacy of the judiciary" ${ }^{35}$.

Es cierto que la doctrina de Coke, en su particular significado de doctrina que daba al juez sólo el poder de declarar el common law, fue superada en Inglaterra por la teoría constitutiva -desarrollada sobre todo por Bentham y Austin- ${ }^{36}$. No obstante, la Revolución de 1688 no hizo desaparecer la noción de que el Parlamento y la ley son sometidos al common law. Tampoco es adecuado sustentar que el juez, a partir de ese momento, pasó a estar sometido al legislativo, ni mucho menos que el derecho de las colonias pasó a deber respeto únicamente a la producción del Parlamento.

El Parlamento, con la Revolución Gloriosa, venció la larga lucha contra el absolutismo del rey. Delante de la preocupación en contener los arbitrios del monarca, los jueces siempre estuvieron al lado del Parlamento, llegando a mezclarse con éste. Así, no hubo alguna necesidad de afirmar la prevalencia de la ley -como producto del Parliament- sobre los magistrados, pero sí la fuerza del derecho común delante del poder real. Además, la Revolución Puritana no objetivó destruir el derecho antiguo, sino, muy por el contrario, se pautó por la afirmación del common law contra el rey.

Así, toda y cualquier norma elaborada por el legislativo estaría insertada dentro del common law, en la búsqueda de la afirmación de los derechos y libertades del pueblo inglés contra el rey ${ }^{37}$. La Revolución, bien por eso, no tuvo la pretensión de elevar a una posición suprema o la intención de dotar al Parlamento de un poder absoluto mediante la producción del derecho.

Más que a la ley, fue necesario dar importancia al common law -o al derecho de la historia y de las tradiciones del pueblo inglés- para contener el poder real. De modo que la idea de supremacy of the English parliament no significó, simplemente, la sumisión del poder real a la norma producida por el legislativo, sino la sumisión completa del rey al derecho inglés. Este derecho sometía al monarca, conteniendo sus excesos, pero también determinaba el contenido de la producción legislativa, que, sin lugar a dudas, no podía ser contrario al common law $w^{38}$.

\footnotetext{
$35 \quad$ Ibídem, p. 40.

36 MACCORMICK, Neil. Can stare decisis be abolished? p. 204.

37 ZAGREBELSKY, Gustavo. Il dirito mite - Legge, diritti, giustizia. Torino: Einaudi, 1992. p. 35.

38 ARGÜELLES, Juan Ramón de Páramo; ROIG, Francisco Javier Anzuátegui. Op. cit., p. 786 y ss.
} 
De cualquier forma, es cierto que el principio de la supremacy of the English parliament no tuvo la menor intención de someter el juez al Parlamento o incluso el objetivo de impedir al juez afirmar el common law, si fuese el caso, contra la propia ley. Este principio tuvo la intención de pasar la noción de supremacía del derecho sobre el monarca y no el propósito de significar omnipotencia de la ley o absolutismo del Parlamento.

Además, la legislación de las colonias no era verdaderamente sometida a la ley inglesa, pero sí vinculada al derecho inglés. El control de la legitimidad de las leyes coloniales se daba a partir del Common Law, incluso porque el Parlamento, como ya fue dicho, estaba sometido a un metaderecho o a un metalenguaje (o common law), y no simplemente escribiendo las primeras líneas de un derecho nuevo, como aconteció con el poder (legislativo) que se instaló con la Revolución Francesa.

De ese modo, el control de legitimidad de los actos de la colonia a partir del derecho inglés y el control de constitucionalidad de las leyes con base en la Constitución americana, no significó un cambio de principios o la sustitución del principio de supremacía del parlamento por el principio de supremacía del poder judicial.

Tal cambio o sustitución puede ser visto apenas si el raciocinio fuera pautado por el significado de que la supremacía del parlamento asumió en el civil law, por derivación de la Revolución Francesa. Sucede que este principio, en Inglaterra, estuvo muy lejos de la idea de la supremacía de la ley sobre el juez, significando, en verdad, supremacía del derecho sobre el monarca y sobre las propias leyes, inclusive a la de las colonias. En esta perspectiva, cuando se controlaba la legitimidad de la ley colonial a partir del derecho inglés, se afirmaba el common law y no la ley (en los moldes del civil law). Y el juez, en esta dimensión, ya se sobreponía al elaborador de la ley divergente. Por consiguiente, el control de constitucionalidad estadunidense significó más una continuidad de lo que una ruptura con el modelo inglés.

Al margen de esto, cabe esclarecer que, si es cierto que el poder del juez del civil law sometido a la Constitución es cercano al del juez estadunidense, crear la norma del caso concreto a partir de la Constitución también es algo bastante similar a crear la norma jurídica a partir del common law o inclusive a declarar el derecho del common law, como ocurría en el derecho inglés primitivo. De ahí que se diga que la noción de creación del derecho, típica del derecho jurisprudencial, se opone a la aplicación estricta de la ley, propia a la tradición del civil law.

\section{UN ESCLARECIMIENTO: LOS DIFERENTES SIGNIFICADOS DE LA "SUPREMACíA DEL PARLAMENTO" EN INGLATERRA Y FranCia}

La supremacy of the English parliament tiene un significado completamente distinto al de la supremacía del legislativo y del principio de legalidad, tal como fueron vistos por la Revolución Francesa. 
La afirmación del Parlamento, subrayada por la Revolución Inglesa de 1688, no tuvo el propósito de marcar el inicio de un nuevo derecho, como ya fue dicho. Su carácter fue conservador. La Revolución no fue dotada de verdadero "espíritu revolucionario", no deseó desconsiderar el pasado y destruir el derecho ya existente, sino, por el contrario, confirmarlo y hacerlo valer contra un rey que no lo respetaba ${ }^{39}$.

Por lo tanto, en lugar de pretender instituir un nuevo derecho mediante la afirmación de la superioridad -en verdad absolutismo- del Parliament en los moldes de la Revolución Francesa, la Revolución Gloriosa instituyó un orden en el que los poderes del monarca estuviesen limitados por los derechos y libertades del pueblo inglés.

Nótese que la noción del rule of law and not of men no significó apenas el topos aristotélico del gobierno de las leyes en sustitución al gobierno de los hombres, sino, sobre todo, la lucha histórico-concreta que el parlamento inglés trabó y ganó contra el absolutismo ${ }^{40}$.

El ordenamiento de la Revolución Puritana se caracterizó por la sumisión del poder del monarca, en su ejercicio y actuación, a determinadas condiciones, así como por la existencia de criterios reguladores de la relación entre él y el Parlamento. En este ordenamiento tiene destaque el célebre Bill of Rights, editado en el primero año de la Revolución, en 1689, al cual Guillermo de Orange fue obligado a someterse para ascender al trono, mediante una especie de acuerdo entre el rey y Parlamento, visto como representante del pueblo. Destáquese que el Bill of Rights, aunque tenga entre sus principios fundamentales la protección de la persona y de la propiedad y determinadas garantías procesales y dimensiones de libertad política, es marcado, por encima de todo, por la sumisión del soberano a la ley ${ }^{41}$.

No obstante la Revolución Inglesa haya vencido al absolutismo, con ella el Parlamento no asumió el poder absoluto, como ocurrió en la Revolución Francesa. Como anota Gustavo Zagrebelsky, en la tradición de Europa Continental la lucha contra el absolutismo significó la pretensión de sustituir el rey por otro poder absoluto, la Asamblea Soberana, al paso que, en Inglaterra, la batalla contra el absolutismo consistió en oponer a las pretensiones del rey los privilegios y libertades tradicionales de los ingleses, representados y defendidos por el Parlamento ${ }^{42}$. Así, mientras en Francia el legislativo se revistió del absolutismo por medio de la producción de la ley, en Inglaterra la ley representó, además del criterio de contención del arbitrio real, un elemento que se insertó en el tradicional y antiguo régimen del common law.

\footnotetext{
39 ARGÜELLES, Juan Ramón de Páramo; ROIG, Francisco Javier Ansuátegui. Op. cit., p. 787.

40 ZAGREBELSKY, Gustavo. Op. cit., p. 36 y ss.

41 ArgüElles, Juan Ramón de Páramo; RoIg, Francisco Javier Ansuátegui. Op. cit., pp. 787-788.

42 ZAGREBELSKY, Gustavo. Op. cit., p. 37.
} 
Como la ley era imprescindible para la realización de los objetivos de la Revolución Francesa, y los jueces no merecían confianza, la supremacía del parlamento ahí fue vista como sujeción del juez a la ley, prohibición que se extendió, incluso, a la posibilidad de interpretarla para no distorsionarla y, así, frustrar los objetivos del nuevo régimen. Al contrario, teniéndose en vista que en Inglaterra la ley no objetivaba expresar un derecho nuevo, sino, representaba mero elemento introducido en un derecho ancestral (el cual, antes de merecer repulsión, era anclado en la historia y en las tradiciones del pueblo inglés), y más aún si el juez era visto como un "amigo" del poder que se instalara (una vez que siempre luchara, conjuntamente con el legislador, contra el absolutismo del rey), no hubo cualquier intención o necesidad de someter al juez inglés a la ley.

Además de la ley nunca haber anulado el poder del juez, los propios principios de la Revolución Inglesa le daban condición para controlar los actos legislativos a partir del common law, ya que el Parlamento, incluso siendo supremo delante del monarca, era sometido a aquel. Sin embargo, en Francia -como quedará más claro a continuación-, la supremacía del parlamento objetivó amarrar al juez al texto de la ley, transformándolo en alguien destituido de poder creativo y de imperium.

\section{LA SUPERACIÓN DEL IUSNATURALISMO RACIONALISTA POR EL POSITIVISMO Y LAS CONCEPCIONES DE JUDGE MAKE LAW Y DEL JUGE BOUCHE DE LA LOI}

Se sabe que la superación del iusnaturalismo racionalista por el positivismo fue marcada por la idea de que el derecho depende de la voluntad. Partiendo de la premisa de que el derecho se traduce a partir de una voluntad, los teóricos positivistas del common law no tuvieron dificultad para demostrar que el derecho no estaba en la tradición o en las costumbres del pueblo -como sustentaban Blackstone y los partidarios de la teoría declaratoria de la jurisdicción- sino que estaría constituido o creado por la decisión judicial.

Así, mientras en el civil law el declive del iusnaturalismo racionalista dio origen a la era de la Codificación, en el common law se observó el surgimiento de la idea de creación judicial del derecho. En aquella tradición, delante de la estricta separación entre el legislativo y el judicial, la voluntad sólo podría estar en el Parlamento; todavía, en el common Law, en virtud del espacio de poder más amplio deferido a los jueces, la voluntad fue confiada al poder judicial. Se torna importante percibir que la conclusión de que, en el civil law, el derecho estaría en el Parlamento, fue coherente -a partir de una visión estrictamente marcada por la teoría positivistacon la idea de que el juez crearía derecho.

Nótese que eso no sólo demuestra que el common law confió y apostó en el poder judicial, mientras que el civil law esclavizó a los jueces al parlamento, pero también que la superación del iusnaturalismo racionalista por el positivismo tuvo efectos 
completamente diversos en los dos sistemas, habiendo colaborado -ciertamente que en términos esencialmente teóricos- para la formación de las concepciones antagónicas de juge bouche de la loi (juez boca de la ley) y de judge make law (juez creador del derecho).

Recuérdese, para estos efectos, que la admisión de la tesis de que el juez crea el derecho tuvo fundamento en la doctrina positivista de Bentham, que no podía entender en la decisión judicial la declaración de un derecho pre-existente fundado en la naturaleza y en la razón de las cosas, sino apenas la creación del derecho.

En este sentido, para distinguir los sistemas, incluso en sus orígenes, no basta hablar que en uno el juez crea derecho y, en el otro, declara la ley, siendo imprescindible comprender que solamente en el common law el juez mereció confianza y espacio en la esfera del poder y que la afirmación de que el "juez crea derecho" constituyó un slogan de una de las vertientes doctrinarias que se presentaron en ese sistema jurídico.

A propósito, en lo atinente a este último punto, es bueno rememorar que, en el common law, continúa discutiéndose al respecto de la naturaleza de la jurisdicción, si es declaratoria o constitutiva. Tal cuestión fue objeto de reciente e importante debate entre Herbert Hart ${ }^{43}$-quien sustenta el papel creativo de la jurisdicción-y Ronald Dworkin ${ }^{44}$-quien lo niega. En verdad, Dworkin es uno de los integrantes de un poderoso y creciente núcleo de pensamiento incrustado en negar la naturaleza positivista del precedente y en proponer una visión "interpretativista" para comprenderse el common law, con la consecuente reinserción en el debate de la teoría declaratoria de la jurisdicción, aunque obviamente, sobre un ropaje contemporáneo ${ }^{45}$.

\section{EL JUEZ COMO “BOUCHE DE LA LOI”}

Antes de la revolución francesa, los miembros del poder judicial francés constituían una clase aristocrática no sólo sin algún compromiso con los valores de igualdad, de fraternidad y de libertad, se mantenían lazos visibles y espurios con otras clases privilegiadas, especialmente con la aristocracia feudal, en cuyo nombre actuaban bajo las togas. En esa época, los cargos judiciales eran comprados y heredados, lo que hacía suponer que el cargo de magistrado debería ser usufructuado como si fuese una propiedad particular capaz de rendir frutos personales.

43 HART, Herbert L. A. The concept of law. Oxford: Clarendon Press, 1993 (esp. Formalism and rule-skepticism e Postscript).

44 DWORKIN, Ronald. Taking rights seriously. Cambridge: Harvard University Press, 1978 (esp. The model of rules e Hard cases); e Law's empire. Cambridge: Harvard University Press, 1978.

45 Ver BANKOWSKI, Zenon; MACCORMICK, Neil; MORAWSKI, Lech; MIGUEL, Alfonso Ruiz. Op. cit., p. 485. 
Los jueces pre-revolucionarios se negaban a aplicar la legislación que era contraria a los intereses de sus protegidos e interpretaban las nuevas leyes de modo a mantener el statu quo y a no permitir que las intenciones progresistas de sus elaboradores fuesen alcanzadas. No había cualquier imparcialidad para "juzgar".

La preocupación en desenvolver un nuevo derecho y permitir el florecimiento de una nueva sociedad exigió la admisión de los argumentos de Montesquieu ${ }^{46}$, aceptándose la necesidad de separación de los poderes e imponiéndose, sobretodo, una clara distinción entre las funciones del legislativo y del judicial. Se volvió imprescindible limitar la actividad del judicial, subordinándolo de forma rígida al Parlamento, cuyos habitantes deberían representar el deseo del pueblo ${ }^{47}$.

De acuerdo con Montesquieu, el "poder de juzgar" debería ser ejercido a través de una actividad puramente intelectual, cognitiva, no productiva de "derechos nuevos". Esa actividad no sería limitada sólo por la legislación, sino también por la actividad ejecutiva, que tendría el poder de ejecutar las decisiones que constituyen el "poder de juzgar". En ese sentido, el poder de los jueces quedaría limitado a afirmar lo que ya había sido dicho por el legislativo, debiendo el juzgamiento ser sólo "un texto exacto de la ley" ${ }^{4}$. Por eso, Montesquieu acabó concluyendo que "el poder de juzgar" era, de cualquier forma, un "poder nulo", (en quelque façon, nulle).

Así, confirió el poder de crear el derecho sólo al legislativo. La prestación judicial debería restringirse a la mera declaración de la ley, dejándose al ejecutivo la tarea de ejecutar las decisiones judiciales.

Para que se pudiese limitar el poder del juez a la declaración de la ley, la legislación debería ser clara y capaz de dar regulación a todas las situaciones conflictivas. Los Códigos deberían ser claros, coherentes y $\operatorname{completos}^{49}$. El miedo del arbitrio

46 De l'esprit des lois (Del espíritu de las leyes) publicado por la primera vez en 1748.

47 Ver GROTE, Rainer. Op. cit., p. 4.

48 Véase: TARELLO, Giovanni. Storia della cultura giuridica moderna. Assolutismo e codificazione del diritto. Bologna: Il Mulino, 1976. p. 280.

49 "El paradigma liberal del derecho expresó, hasta las primeras décadas del siglo XX, un consenso de fondo muy difundido entre los especialista en derecho, preparando, así, un contexto de máximas de interpretación no cuestionadas para la aplicación del derecho. Esa circunstancia explica por qué muchos pensaban que el derecho podía ser aplicado a su tiempo, sin el recurso a principios necesitados de interpretación o a 'conceptos llave' dudosos" (HABERMAS, Jürgen. Direito e democracia. Rio de Janeiro: Tempo Brasileiro, 1997. p. 313). "Con base en tales premisas, la ciencia del derecho podía afirmar que las disposiciones legislativas nada más eran que partículas constitutivas de un edificio jurídico coherente y que, por lo tanto, el intérprete podía retirar de ellas, inductivamente o mediante una operación intelectiva, las estructuras que lo sustentaban, esto es, sus principios. Ese es el fundamento de la interpretación sistemática y de la analogía, dos métodos de interpretación que, en la presencia de una laguna - esto es, de la falta de una disposición expresa para resolver una controversia jurídica- permitían individualizar la norma precisa en coherencia con el sistema. Por lo tanto, la sistematicidad acompañaba la plenitud del derecho" (ZAGREBELSKY, Gustavo. Op. cit., p. 43). "En la 
judicial, derivado de la experiencia del Ancien Régime, no sólo exigía la separación entre el poder de crear el derecho y el poder de juzgar, como también orientaba la arquitectura legislativa deseada. Además de eso, el racionalismo exacerbado, típico de la época, hacía acreditar que la tarea judicial podría ser sólo identificar la norma aplicable para la solución del litigio.

Entre tanto, la codificación, por sí sola, no puede explicar la distinción entre el common law y el civil law. No se piense que el civil law está caracterizado por los Códigos y por la tentativa de omnisciencia de la legislación, mientras que el common law tiene una característica exactamente contraria. El common law también tiene intensa producción legislativa y varios Códigos. Lo que realmente varía del civil law para el common law es el significado que se atribuye a los Códigos y a la función que el juez ejerce al considerarlos. En el common law, los Códigos no tienen la pretensión de cerrar los espacios para que el juez no pueda pensar más; por lo tanto, no se preocupan en tener todas las reglas capaces de solucionar los casos conflictivos. Y eso, porque en este sistema, jamás se creyó o se tuvo la necesidad de acreditar que podría existir un Código que eliminase la posibilidad de el juez interpretar la ley. Nunca se pensó en negar al juez de esta tradición el poder de interpretar la ley. De modo que, si alguna diferencia existe, en lo que respecta a los Códigos, entre el civil law y el common law, tal distinción está en el valor o en la ideología subyacente a la idea de Código.

Es preciso prestar atención, sobretodo, a la diferencia entre la historia del poder judicial en el common law y la historia del derecho continental europeo, en particular a los fundamentos del derecho francés post-revolucionario. En Inglaterra, al contrario de lo que ocurrió en Francia, los jueces no sólo constituyeron una fuerza progresista preocupada en proteger al individuo y en poner frenos en el abuso del gobierno, puesto que también desempeñaron un papel importante para la centralización del poder y para la superación del feudalismo. En aquel país, la unificación del poder se dio de forma razonablemente rápida, con la eliminación de la jurisdicción feudal y de otras jurisdicciones paralelas. Y los jueces colaboraron para esta unificación, afirmando el derecho de ancestral tradición en la nación, sin cualquier necesidad de rechazo a la tradición jurídica del pasado.

La Revolución Francesa, sin embargo, procuró crear un derecho que fuese capaz de eliminar el pasado y las tradiciones hasta entonces heredadas de otros pueblos, mediante el olvido no sólo del derecho francés más antiguo, como también de la negación de la autoridad del ius commune. El derecho común había de ser

edad liberal -la edad en la que se encierra en 1914 entre los esplendores de la gran guerra-, el sistema normativo gravita completamente en torno al Código Civil. El Código Civil de 1865 contiene los principios generales, que orientan la regulación de las particulares instituciones o materias y que, en última instancia, sirven para colmar las lagunas del ordenamiento" (IRTI, Natalino. Leyes especiales (del mono-sistema al poli-sistema). La edad de la descodificación. Trad. Luis Rojo Jauría. Barcelona: Bosch, 1992. p. 93). 
substituido por el derecho nacional. Tal derecho tenía que ser claro y completo para no permitir cualquier interferencia judicial en el desarrollo del derecho y del poder gubernamental. No había cómo confiar en los jueces que hasta entonces estaban al lado de los señores feudales manteniendo fuerte oposición a la centralización del poder. Véase, entonces, que el derecho francés, además de rechazar el derecho común del civil law y de buscar instituir un derecho nacional nuevo, tuvo la necesidad de legitimarlo mediante la subordinación del poder del juez al poder del Parlamento. El derecho contaría con un grave e insuperable déficit democrático en caso fuese interpretado por los magistrados. O mejor, había motivo para no dar a los jueces el poder de interpretar las normas trazadas por los representantes del pueblo.

Las historias de poder en el common law y en el civil law fueron las responsables por las diferentes funciones atribuidas a los jueces de esos sistemas jurídicos. Mientras tanto, es necesario señalar que la falta de semejanza entre las funciones del juez del common law y de civil law restó, en buena cuenta, el papel y en la intención de los inspiradores del Estado legislativo francés. La Revolución Francesa, como toda revolución, quedo resentida de la fuerte dosis de ilusiones románticas y utopías, generando dogmas como el de la prohibición de que el juez interprete la ley.

\section{EL PROBLEMA DE LA INTERPRETACIÓN DE LA LEY EN EL CIVIL LAW}

Como ya fue dicho, la Revolución Francesa pretendió prohibir al juez el interpretar la ley. Se imaginaba que, con una legislación clara y completa, le sería posible al juez simplemente aplicar la ley y, de esta manera, solucionar los casos litigiosos sin la necesidad de extender o limitar su alcance y sin nunca depararse con su ausencia o incluso con el conflicto entre las normas. En la excepcionalidad del conflicto, obscuridad o falta de ley, el magistrado obligatoriamente debería presentar la cuestión al legislativo para la realización de la "interpretación autorizada".

En efecto, la Ley Revolucionaria de agosto de 1790 no sólo afirmó que "los tribunales judiciales no tomarán parte directa o indirectamente, en el ejercicio del poder legislativo, ni impedirán suspender la ejecución de las decisiones del poder legislativo" (Título II, art. 10), sino, también que los tribunales "se reportarán al cuerpo legislativo siempre que así lo considerasen necesario, a fin de interpretar o editar una nueva ley" (Título II, art. 12).

Se afirmó que el juez, al no poder identificar la norma aplicable a la solución del caso, debería recurrir al legislativo. Se suponía, es claro, que estas situaciones serían raras y que tenderían a desaparecer. De cualquier forma, poca cosa puede expresar en forma tan marcante la pretensión revolucionaria de limitar al poder judicial.

Algo similar aconteció anteriormente en el derecho prusiano. El célebre Código Prusiano (Allgemeines Landrecht für die Preußischen Staaten), elaborado por 
Federico II - el Grande - en 1794, contenía más de 17.000 artículos, revelando el intento de regular todas las situaciones fácticas por más específicas que fuesen. Del mismo modo que el Código Napoleónico - que tenía 2.281 artículos- el objetivo de Federico fue el de hacer un derecho a prueba de jueces ${ }^{50}$. El primer rey de Prusia no se dio por satisfecho con los 17.000 artículos de su Código, habiendo también prohibido a los jueces poder interpretarlos y, en la misma senda de la Revolución Francesa de 1790, creó una comisión legislativa a la cual los jueces tenían el deber de recurrir en casos de duda sobre la aplicación de una norma. El juez que cayese en la tentación de interpretar el Código incidiría en la "grande ira" de Federico y sufriría severos castigos.

Aún más interesante para nuestro propósito es la historia de la Corte de Casación Francesa. Este tribunal también fue instituido en 1790, con el nítido objetivo de limitar el poder judicial mediante la cesación de las decisiones que no fuesen coherentes con el derecho creado por el parlamento ${ }^{51}$. Es posible decir que la Cassation fue instituida como una válvula de escape contra la aplicación incorrecta de la ley y la no presentación del caso a la interpretación autorizada del legislativo. Sin embargo, tal vez ya se vislumbraba la dificultad práctica en exigirse a los jueces la exposición de sus dudas al legislativo, bien como el trabajo excesivo y prácticamente inviable que sería sometido al legislador en caso todas las dificultades interpretativas le fuesen anunciadas ${ }^{52}$.

Aunque fuese llamada de Corte, ese órgano no hacía parte del Poder Judicial, constituyendo instrumento destinado a proteger la supremacía de la ley. Esta primera naturaleza - no jurisdiccional- de la Casación era compatible con su función de apenas casar o anular las decisiones judiciales que diesen a la ley un sentido indeseado. Sin obligar al juez a requerir la debida interpretación, se impedía que las decisiones que no se limitasen a aplicar la ley tuviesen efectos. En lugar de utilizarse los instrumentos de la "consulta interpretativa autorizada", se prefería algo más factible, esto es, casar la interpretación equivocada.

Subráyese que a Cour de Cassation fue instituida únicamente para casar la interpretación incorrecta, y no para establecer la interpretación correcta o para decidir en substitución a la decisión proferida por el juez ordinario. Recuérdese que ella no era si quiera considerada un órgano jurisdiccional y, por eso mismo, no podía decidir. De esa forma, la Cassation no se sobreponía al órgano judicial ordinario por tener el poner de proferir la última decisión, pero sí por tener el poder para afirmar cómo la ley no debería ser interpretada.

\footnotetext{
50 MERRYMAN, John Henry; PÉREZ-PERDOMO, Rogelio. Op. cit., p. 39.

51 Ver CALAMANDREI, Piero. La cassazione civile - I. Storia e legislazione. Torino: Fratelli Bocca, 1920. p. 426 y ss.; TARUFFO, Michele. Il vertice ambiguo - Saggi sulla cassazione civile. Bologna: Il Mulino, 1991. p. 29 y ss.

52 MERRYMAN, John Henry; PÉREZ-PERDOMO, Rogelio. Op. cit., p. 39 y ss.
} 
El tiempo hizo sentir que el momento para afirmar que la ley no debería ser interpretada también sería oportuno para afirmar cómo la ley debería ser interpretada. O sea, la historia muestra que la Casación, de órgano destinado a simplemente anular la interpretación errada pasó a órgano de definición de la interpretación correcta. Tal evolución igualmente abrigó a la mutación de la característica del órgano estatal, que asumió la naturaleza jurisdiccional de órgano incumbido de participar del proceso de producción de decisiones judiciales.

Además, la Corte de Casación no sólo adquirió el semblante de órgano jurisdiccional, como pasó a constituir el tribunal de cúpula del sistema, sobreponiéndose a los tribunales ordinarios. Su función se tornó la de dictar y asegurar la interpretación correcta de la ley, evitando que los tribunales inferiores consolidasen interpretaciones equivocadas.

Así, la Corte llega a un estadio en el que no hay más control no jurisdiccional de las interpretaciones judiciales. Hay, ahora, preocupación en fijar, a través del propio Poder Judicial, la correcta interpretación de la ley y asegurar la uniformidad de la interpretación en el país y en los varios tribunales inferiores. Básicamente, esto se tornó posible por dos motivos. Primero, se adquirió consciencia de que la lectura del texto de la norma implica un acto de comprensión que, así, abre oportunidad para varias definiciones y, por lo tanto, interpretaciones. Además, se convirtió incuestionable que el acto de comprender la ley era incumbencia del poder judicial y no del poder legislativo. Lo que pasó a importar, en verdad, fue tan solamente si sería conveniente admitir que el poder judicial exprimiese, en un mismo instante histórico, varias interpretaciones para la misma ley.

El punto tiene relevancia insospechada. No obstante, cabe subrayar que, si la función del Superior Tribunal de Justicia de Brasil es velar por la integridad del derecho infraconstitucional, su aspecto no es muy diferente de aquella que la Casación francesa asumió con el pasar del tiempo. También en el sistema brasilero hay preocupación en saber cómo el Judicial debe exprimirse delante de la inapartabilidad de diversas interpretaciones, siendo la solución para el problema la imposición de la interpretación del Superior Tribunal de Justicia sobre los tribunales ordinarios.

De cualquier forma, es imprescindible e importante notar que la Corte de Casación, hoy tribunal jurisdiccional destinado a asegurar la interpretación correcta y la uniformidad de la interpretación, tiene origen en un órgano no jurisdiccional instituido para evitar que la voluntad de los jueces se sobrepusiese a la voluntad de los habitantes del parlamento. De órgano destinado a garantizar la supremacía de la ley para órgano destinado a afirmar y velar por una única interpretación de la ley: he ahí la verdadera mutación por la cual la Casación pasó.

Sin embargo, es sorprendente que la cultura jurídica del civil law no se haya dado cuenta de que tal mutación no podría permitir la manutención de dos dogmas -que echan raíces en la Revolución Francesa- de que la ley constituye la seguridad 
de la que el ciudadano necesita para vivir en libertad y en igualdad y de que el juez sólo actúa la voluntad de la ley ${ }^{53}$.

\section{LA CERTEZA JURídicA COMO GARANTía DE SEGURIDAD}

Para la Revolución Francesa, la ley sería indispensable para la realización de la libertad y de la igualdad. Por este motivo, se entendió que la certeza jurídica sería igualmente indispensable delante de las decisiones judiciales, una vez que, en caso los jueces pudiesen producir decisiones desafinadas de la ley, los propósitos revolucionarios estarían perdidos o serían inalcanzables.

Así, mantener al juez aprisionado a la ley sería sinónimo de seguridad jurídica. Montesquieu hizo coro por la seguridad jurídica fundada en la estricta aplicación de la ley cuando dijo que, si los juzgamientos "fuesen una opinión particular del juez, se viviría en una sociedad sin saber precisamente los compromisos que en ella son asumidos" 54 . Ese pasaje de la doctrina de Montesquieu, según advierte Giovanni Tarello, evidencia una ideología que sugiere que la libertad política, entendida como seguridad psicológica del individuo, se realiza por medio de la certeza del derecho ${ }^{55}$.

La certeza del derecho estaría en la imposibilidad de interpretar la ley por parte del juez, o mejor dicho, en la propia ley. El punto tiene enorme relevancia. Nótese que el civil law no sólo imaginó, utópicamente, que el juez sólo actuaría la voluntad de la ley, como todavía se supuso que, en virtud de la certeza jurídica que de ella derivaría, el ciudadano tendría seguridad y previsibilidad en el trato de las relaciones sociales. Además, se imaginó que la ley sería suficiente para garantizar la igualdad de los ciudadanos.

Esto significa que, en los países que no necesitaron de ilusionarse con el absurdo de que el juez no podía interpretar la ley, naturalmente se aceptó que la seguridad y la previsibilidad tendrían que ser buscadas en otro lugar. Y, ¿qué lugar sería ese? Ahora bien, exactamente en los precedentes o, precisamente, en el stare decisis.

La seguridad y la previsibilidad son obviamente valores deseados por ambos sistemas. Sin embargo, se supuso en el civil law que tales valores serían realizados por medio de la ley y de su estricta aplicación por los jueces, mientras que en el common law, por nunca haber existido duda de que los jueces interpretasen la ley y, por eso, pueden proferir decisiones diferentes, se entendió en la fuerza vinculante de los precedentes el instrumento capaz de garantizar la seguridad y la previsibilidad la cual necesita la sociedad para desarrollarse

53 Ver GROSSI, Paolo. Mitologie giuridiche della modernità. 2. ed. Milano: Giuffrè, 2005. p. 55 y ss.

54 MONTESQUIEU, Barón de (Charles-Louis de Secondat). Op. cit., p. 158; ver TARELLO, Giovanni. Op. cit., p. 194.

55 TARELLO, Giovanni. Op. cit., p. 294. 
No obstante, la cuestión puede ser definitivamente desnudada sólo a partir del descubrimiento del motivo por el cual la doctrina del civil law, incluso después de haber admitido la obviedad de que el juez interpreta la ley, y, más que eso, que los jueces frecuentemente divergen y expiden innumerables decisiones diferentes al aplicar el texto de la ley, continuó aceptando que la ley sería suficiente para garantizar la seguridad y la previsibilidad.

Se trata de algo realmente curioso. Aunque la praxis haya constatado que de nada ayuda la ley cuando el ciudadano no sabe qué esperar de los jueces, la única preocupación de la doctrina ha sido la de demostrar que, a pesar de haberse tornado evidente que el juez presta tutela jurisdiccional yendo más allá de la mera aplicación de la ley, eso no significa negación del principio de separación de poderes. O mejor aún, la doctrina no tomó consciencia de que, delante de la variedad de las decisiones y de las interpretaciones de la ley, sería necesaria una elaboración dogmática capaz de garantizar la seguridad e igualdad. Hay que decirse, sin cualquier pudor, que la doctrina del civil law cometió pecado grave al encubrir la necesidad de un instrumento capaz de garantizar la igualdad delante de las decisiones, fingiendo creer que la ley sería bastante y prefiriendo preservar el dogma en vez de denunciar la realidad y la funesta consecuencia de ella derivada.

En resumen: no hay cómo ignorar, tanto en el common law como en el Civil Law, que una misma norma jurídica puede generar diversas interpretaciones y, por consecuencia, variadas decisiones judiciales. Todavía, el common law, ciertamente con la colaboración de un ambiente político y cultural propicio, rápidamente intuyó que el juez no podría ser visto como mero revelador del derecho consuetudinario, llegando a atribuirle la función de creador del derecho, mientras el civil law permanece preso a la idea de que el juez simplemente actúa la voluntad del Derecho. De modo que el common law puede fácilmente vislumbrar que la certeza jurídica sólo podría ser obtenida mediante el stare decisis, al paso que el civil law, por estar todavía encubriendo la realidad, en los libros habla sobre la certeza jurídica en la aplicación de las leyes, pero, en otro lugar, se siente absorto delante de la desconfianza de la populación, además de envuelto en un enmarañado de reglas que, de forma no sistemática, intentan dar alguna seguridad y previsibilidad al jurisdiccionado.

\section{EL INDIVIDUALISMO DEL JUEZ DEL CIVIL LAW}

Aunque las decisiones, en el sistema del civil law, varíen constantemente de señal, cambiando de sentido al sabor del viento, eso debe ser visto como una patología o como un equívoco que, lamentablemente, se arraigó en nuestra tradición jurídica.

Se supuso que los jueces no deben algún respeto a las decisiones pasadas, llegándose a alegar que cualquier intento de vincular el juez al pasado interferiría sobre su libre convencimiento y sobre su libertad de juzgar. 
Se trata de un grosero mal entendido, derivado de la falta de comprensión de que la decisión es el resultado de un sistema y no algo construido de forma individualizada por un sujeto que puede hacer valer su voluntad sobre todos los que lo rodean y, así, sobre el propio sistema del cual hace parte. Imaginar que el juez tiene el derecho de juzgar sin someterse a sus propias decisiones y a las de los tribunales superiores es no entender que el magistrado es una pieza en el sistema de distribución de justicia y, más que eso, que este sistema no le sirve únicamente a él, sino, al pueblo.

Como es obvio, el juez o tribunal no deciden para sí, sino para el jurisdiccionado. Por eso, poco debe importar para el sistema si el juez tiene alguna posición personal acerca de alguna cuestión de derecho, que difiera de los tribunales que le son superiores. Lo que realmente debe tener significado es la contradicción propia del juez por cuanto este pueda decidir sobre cuestiones iguales, de forma diferente, o decidir de forma distinta a la del tribunal que le es superior. El juez que se contraria en su propia decisión, sin la debida justificativa, está muy lejos del ejercicio de cualquier libertad, estando más próximo a la práctica de un acto de insanidad. Mientras sucede eso, el juez que contraría la postura del tribunal, consciente de que a éste le cabe la última palabra, practica un acto que atentase contra la lógica del sistema, significa desprecio al Poder Judicial y desconsideración para con los usuarios del servicio jurisdiccional.

Ha llegado el momento de colocarse punto final al agotador discurso de que el juez tiene la libertad herida cuando es obligado a decidir de acuerdo a los tribunales superiores. El juez, además de libertad para juzgar, tiene deberes con el Poder del cual hace parte y con el ciudadano. Posee el deber de mantener la coherencia del ordenamiento y de velar celosamente por la respetabilidad y por la credibilidad del Poder Judicial. Además de eso, no debe transformar su propia decisión, a los ojos del jurisdiccionado, en un "nada" o peor, en obstáculo que necesita ser contorneado mediante la interposición del recurso al tribunal superior, violando los derechos fundamentales a la tutela efectiva y a la duración razonable del proceso. Por otra parte, es cierto que el juez deja de respetarse a sí mismo y al jurisdiccionado cuando niega sus propias decisiones. Se trata de algo poco más que contradictorio, caminando próximo a la orilla de lo inconcebible.

Como es evidente, delante de casos distintos el juez no necesita decidir de acuerdo con el tribunal superior o en conformidad con la decisión que anteriormente profirió. Le cabe, en esta situación, realizar lo que el common law conoce por distinguished, esto es, la diferenciación del caso que está próximo a ser juzgado.

Subráyese que no hay poder que no tenga responsabilidad por sus decisiones. No obstante, es poco plausible que alguien pueda justificar su responsabilidad cuando decide casos iguales de forma desigual. "Treat like cases alike", es el principio que, visto en su significado originario, siempre estuvo en la base del common law, consistiendo una de las principales razones de su coherencia, así como de la con- 
fianza y del respeto en los jueces. Tratar de la misma forma casos similares es algo fundamental para la estabilidad del poder.

\section{EL IMPACTO DEL CONSTITUCIONALISMO EN EL CIVIL LAW}

La noción de norma general, abstracta, coherente y fruto de la voluntad homogénea del parlamento, típica del derecho de la Revolución Francesa, no sobrevivió a los acontecimientos históricos ${ }^{56}$. Entre otras cosas, se vivió la experiencia de que la ley podría ser creada de modo contrario a los intereses de la populación y a los principios de justicia.

Así, se tornó necesario rescatar la substancia de la ley para encontrar los instrumentos capaces de permitir su conformación a los principios de justicia. Esta "substancia" y estos "principios" fueron infiltrados en las Constituciones, que perdieron sus resquicios de flexibilidad para tornarse "rígidas" en el sentido de no ser pasibles de modificación por la legislación ordinaria. La Constitución está dotada de plena eficacia normativa y, así, la ley pierde su puesto de supremacía, pasando a subordinarse a ella ${ }^{57}$.

La ley pasa a encontrar límite y contorno en los principios constitucionales, lo que significa que deja de tener apenas legitimación formal, quedando substancialmente amarrada a los derechos positivados en la Constitución. La ley no vale más por sí, pero depende de su adecuación a los derechos fundamentales. Si antes era posible decir que los derechos fundamentales estaban circunscritos a la ley, se torna exacto, ahora, afirmar que las leyes deben estar en conformidad con los derechos fundamentales..$^{58}$

El propio principio de legalidad pasa a tener otro significado, dejando de tener contenido sólo formal para adquirir contenido substancial. El principio de legalidad pasa a ligarse al contenido de la ley, o mejor aún, a la conformación de la ley con los derechos fundamentales.

56 Ver CLASSEN, C. D. Gesetzesvorbehalt und Dritte Gewalt. Juristenzeitung, vol. 58, issue 14, 2003, p. 693-701; HERMES, G. Grundrechtschutz durch Privatrecht auf neuer Grundlage?. NJW, München/Frankfurt am Main, Beck, 1990, pp. 1764-1768.

57 Ver PERLINGIERI, Pietro. Il diritto civile nella legalità costituzionale. Napoli: Edizioni Scientifiche Italiane, 1991; STÜRMER, Rolf. Einwirkungen der Verfassung auf das Zivilrecht und den Zivilprozessrecht. NJW, München/Frankfurt am Main, Beck, 1979, pp. 2334-2338; HÄBERLE, Peter. Leistungsrecht im sozialen Rechtsstaat. Recht und Staat - Festschrift für K. Küchenhoff. Berlin: Duncker \& Humblot, 1972.

58 ALEXY, Robert. "Los derechos fundamentales en el estado constitucional democrático". En: FERRAJOLI, Luigi et al. Los fundamentos de los derechos fundamentales. Madrid: Trotta, 2001. p. 34; SCHEUNER, U. Die Funktion der Grudrechte im Sozialstaat. Die Grundrechte als Richtlinie und Rahmen der Staatstätigkeit. Die öffentliche Verwaltung - DOV, 1971, pp. 505513. 
La mutación del principio de legalidad hizo que Ferrajoli aludiese a una segunda revolución, contrapuesta a la que fue creada con la aparición del antiguo principio de legalidad, el cual provocó, con la afirmación de la omnipotencia del legislador, una alteración de paradigma en relación al derecho anterior al del Estado legislativo. Pero esta segunda revolución también implicó una quiebra de paradigma, substituyendo el principio de legalidad formal por el principio de legalidad substancial ${ }^{59}$.

En una primera visión, alguien podría negar cualquier ruptura de paradigma, prefiriendo entender mera reafirmación de la supremacía del la ley, argumentando que la subordinación del Estado a la ley habría sido llevada a última consecuencia, consistente en la subordinación de la propia legislación a la Constitución, que sería la "ley mayor". Entre tanto, esta lectura constituyó un reduccionismo injustificable del significado de subordinación de la ley a la Constitución o una incomprensión de las tensiones que condujeron a la transformación de la propia noción de derecho. En verdad, la subordinación de la ley a la Constitución no puede ser comprendida como mera "continuación" de los principios del Estado legislativo, pues significa una "transformación" que afecta a las propias concepciones de derecho y de jurisdicción ${ }^{60}$.

No hay duda de que el civil law pasó por un proceso de transformación de las concepciones de derecho y de jurisdicción. Ahora, si el derecho no está más en la ley, pero sí en la Constitución, la jurisdicción no se destina más a declarar la voluntad de la ley, sino a conformar la ley a los derechos contenidos en la Constitución. Tanto es verdad que las jurisdicciones de Europa continental no resistieron a la necesidad del control de constitucionalidad de la ley, aunque hayan reservado esta función a los órganos que, inicialmente, fueron concebidos como no jurisdiccionales, exactamente en homenaje al principio de que el juez no podría inmiscuirse en la tarea del legislativo ${ }^{61}$.

No obstante, más importante que convencer al respecto de la creación judicial del derecho es evidenciar que el juez del civil law pasó a ejercer el papel que, en un único tiempo, es inconcebible delante de los principios clásicos del civil law y tan creativo cuanto el de su colega del common law ${ }^{62}$. El juez que controla la constitucionalidad de la ley obviamente no es sometido a la ley. Su papel, como es evidente,

59 FERRAJOLI, Luigi. Derechos fundamentales. In: FERRAJOLI, Luigi et al. Los fundamentos de los derechos fundamentales. Madrid: Trotta, 2001. p. 53.

60 ZAGREBELSKY, Gustavo. Op. cit., p. 46; IRTI, Natalino. Codice Civile e società politica. 7. ed. Roma: Laterza, 2005.

${ }_{61}$ Ver PICARDI, Nicola. "La vocazione del nostro tempo per la giurisdizione". Rivista Trimestrale di Diritto e Procedura Civile, 2004.

62 Ver MARINONI, Luiz Guilherme. Curso de processo civil - Teoria geral do processo. Op. Cit., vol. 1, p. 104 y ss. 
niega la idea de supremacía del legislativo. Recuérdese que el juez, mediante las técnicas de la interpretación conforme a la Constitución y de declaración parcial de nulidad sin reducción del texto, confiere a la ley sentido distinto del que le dio el legislativo. El aspecto judicial de la imposición del derecho también es clara -o aún más evidente- al prestarse atención a la tarea que el juez ejerce cuando suple la omisión del legislador delante de los derechos fundamentales. Ahora, eso apenas puede significar, a los ojos de los principios y de la tradición del civil law, una afirmación del poder judicial con fuerza de derecho, en los moldes de lo que se concibió en el common law.

Afirmase en el common law que el juez, en la falta del derecho preexistente, realiza actividad creativa. En verdad, esta es una cuestión que el positivismo de Hart pone en toda evidencia: "Habrán siempre ciertos casos jurídicamente no regulados en los que, relativamente a determinado punto, ninguna decisión en cualquiera de los sentidos es dictada por el derecho y, de conformidad, el derecho se presenta como parcialmente indeterminado o incompleto. $\mathrm{Si}$, en tales casos, el juez tuviese que proferir una decisión, en lugar de, como Bentham llegó a abogar en otros tiempos, declararse privado de jurisdicción, o remitir los puntos no regulados por el derecho existente para la decisión del órgano legislativo, entonces debe ejercer su poder discrecional y crear derecho para el caso, en lugar de aplicar meramente el derecho establecido anteriormente" ${ }^{\text {. }}$.

Entretanto, se percibe que hay en el civil law una preocupación en negar u oscurecer -o tal vez tornar irrelevante- el papel que el neoconstitucionalismo impuso al juez. Hay una completa desidia por el significado de la nueva función judicial. No existe algún empeño en resaltar que el juez, en el Estado constitucional, dejó de ser un mero siervo del legislativo. Hay, apenas, cuidado en demostrar que el principio de la separación de poderes se mantiene intacto, como se fuese importante sólo la manutención de los principios. Como es obvio, no se quiere decir que el principio de separación de poderes no tiene más significado o importancia. Se desea, solamente, demostrar que, cuando se intenta acomodar la realidad en la forma de las reglas o de los principios, se corre el riesgo de ver surgir algo que más parece una imagen reflejada a partir de un espejo de circo. El hábito de acomodar realidades a las reglas y a los principios hace que la realidad sea distorsionada e incluso negada. Son las reglas y los principios que deben adquirir otra conformación, adaptándose a las nuevas realidades y no al contrario.

La dificultad en ver el papel del juez bajo el neoconstitucionalismo impide que se perciba que la tarea del juez del civil law, en la actualidad, está muy próxima de la ejercida por el juez del common law. Ahora, es exactamente la ceguera para la aproximación de las jurisdicciones de estos sistemas que no permite entender la relevancia de un sistema de precedentes en el civil law.

$63 \quad$ HART, Herbert L. A. Op. cit., p. 135. 


\section{EL JUEZ DELANTE DE LOS CONCEPTOS INDETERMINADOS Y DE LAS REGLAS ABIERTAS}

Considerándose al juez de la tradición del civil law, esto es, aquel deseado por la Revolución Francesa, se torna inevitable apartarlo del juzgador que decide con base en conceptos indeterminados e en reglas abiertas.

No queda duda que el juez que debe decidir pronunciando las palabras de la ley -como quería Monstequieu - no puede ser confundido con aquel que puede dar significado al concepto indeterminado o concretizar la regla abierta, adoptando la solución que le pareciere oportuna y adecuada al caso concreto.

Como advierten Merryman y Pérez-Perdomo, no se exige mucha imaginación para percibir que cláusulas como la de la buena fe dan al juez gran porción de poder equitativo indefinido, dejándolo casi sin responsabilidad delante de la formulación legislativa ${ }^{64}$.

A propósito, los propios doctrinadores del common law reconocen, cuando miran para el civil law, que en las decisiones acerca de materia constitucional, así como en las que son envueltos la aplicación de cláusulas generales, en las que es frecuente la necesidad de dar concreción al significado de conceptos jurídicos, no hay si quiera cómo admitir la distinción realizada por algunos, entre precedentes interpretativos y precedentes de solución (que crean el derecho). Se alega, en esos casos, que la interpretación tiene tanto alcance y es guiada por argumentos tan frágiles y vagos de la ley escrita, que la decisión podría ser explicada tanto por la teoría interpretativista como por la teoría positivista de la creación judicial del derecho. ${ }^{65} \mathrm{O}$ sea, tal decisión judicial podría ser vista como creación de derecho o como interpretación judicial del derecho.

Por eso mismo, el sistema de precedentes, innecesario cuando el juez sólo aplica la ley, es indispensable en la jurisdicción contemporánea, pues es fundamental para otorgar seguridad a la parte y permitir al abogado tener consciencia de cómo los jueces completan el concepto indeterminado y concretan una regla abierta.

\section{JUDGE MAKE LAW Y DECISIÓN JUDICIAL, EN LA AUSENCIA DE LEY, EN EL CIVIL LAW}

El fin de este ítem no es analizar si el magistrado, en ausencia de regla capaz de regular el caso, crea o no derecho. Se desea, tan sólo, demostrar que la idea de que el juez crea derecho, peculiar al common law, no sirve para separar los sistemas contemporáneos comprendidos en las dos tradiciones, ni mucho menos para justificar la no existencia de un sistema de precedentes.

\footnotetext{
64 MERRYMAN, John Henry; PÉREZ-PERDOMO, Rogelio. Op. cit., p. 53.

${ }_{65}$ Ver BANKOWSKI, Zenon; MACCORMICK, Neil; MORAWSKI, Lech; MIGUEL, Alfonso Ruiz. Op. cit., p. 485.
} 
En verdad, ni si quiera existe unanimidad, en el common law, acerca de la naturaleza de la jurisdicción, si esta es creadora de derechos o no. La cuestión de si los jueces crean derecho fue uno de los principales focos del célebre debate entre Herbert Hart -que sustenta el papel creativo de la jurisdicción- y Ronald Dworkinquien lo niega ${ }^{66}$. Mientras aquel afirma, sin hesitar, que el juez crea el derecho en la falta de regla a permitir la solución del caso, ${ }^{67}$ este, al tratar de los 'hard cases', en el conocido "Taking rights seriously" argumenta que, "inclusive cuando ninguna regla regula el caso, una de las partes puede, todavía así, tener el derecho de ganar la causa" y, "el juez continúa teniendo el deber, incluso en los casos difíciles, de descubrir cuáles son los derechos de las partes y no de inventar nuevos derechos retroactivamente" 68 .

En el importante libro Interpreting precedents, en el que se hace amplio debate comparativo sobre los precedentes en el common law y en el civil law, se encuentra el capítulo intitulado "Rationales for precedent", protagonizado por Bankowski, MacCormick, Morawski y Ruiz Miguel. Estos juristas, al depararse con la influencia de las decisiones de la Corte Europea de Justicia de cara a las Cortes de los Estados-miembro, inclusive sobre sus Tribunales Constitucionales, observan que, en las decisiones relativas a cuestiones constitucionales y cláusulas generales, la prestación judicial opera construyendo principios y dándole efectos concretos, cuando se torna artificial, o incluso ficticio, intentar dibujar una línea demarcatoria entre los precedentes interpretativos y los de creación del derecho ${ }^{69}$.

El insight del grupo de juristas, aliado a la disputa teórica entre Hart y Dworkin, demuestra que la evolución del civil law, ciertamente en virtud del impacto del neoconstitucionalismo, aproximó sensiblemente lo que podría ser visto como creación judicial del derecho e la interpretación judicial.

En el civil law es posible decir que hay "ausencia de ley" cuando el legislador dejó de promulgar norma necesaria a la tutela del derecho fundamental. En otros términos, para que el juez pueda actuar en la ausencia de ley, el legislador debe haber violado el derecho fundamental en su función de mandamiento de tutela. Todavía, tal violación no transfiere al juez el grado de libertad que hasta entonces estaba en las manos del legislador, ya que al juez no le cabe exactamente la tutela normativa del derecho fundamental pero sí el control de la suficiencia de esta tutela, y así, una tutela que satisfaga las exigencias mínimas en su eficiencia ${ }^{70}$.

66 Ver, al respecto, HART, Herbert L.A. Op. cit. (esp. Formalism and rule-skepticism y Postscript); DWORKIN, Ronald. Taking rights seriously, Op. cit. (esp. The model of rules y Hard cases).

67 HART, Herbert L. A. Op. cit., p. 135.

68 DWORKIN, Ronald. Taking rights seriously, Op. cit., p. 12 y ss.

69 BANKOWSKI, Zenon; MACCORMICK, Neil; MORAWSKI, Lech; MIGUEL, Alfonso Ruiz. Op. cit., p. 485.

70 Ver CANARIS, Claus-Wilhelm. Direitos fundamentais e direito privado. Coimbra: Almedina, 2003, pp. 138-139. 
De modo que el juez no detenta el mismo poder del legislador y, por lo tanto, la decisión judicial, aunque sobre la luz de la necesidad de afirmación de los derechos fundamentales, no substituye la ley. Lo que se puede decir, sin cualquier duda, es que el juez no está más limitado a afirmar la ley, pues debe respuesta a la Constitución y, en esa perspectiva su decisión se inserta en un cuadro más amplio, dimensionado por los derechos fundamentales.

El juez estadounidense, subordinado a la fuerza de los derechos fundamentales, detenta mayor legitimidad que aquel que era concebido como judge make law sólo por estar afirmando algo que no había sido dicho por el Parlamento. A propósito, la vigorosa doctrina estadounidense, liderada por Dworkin, sustenta que la dignidad de la decisión judicial nada tiene que ver con el hecho de que el juez pueda crear derecho o no, sino con la circunstancia de que el juez pueda decidir a partir de principios y fundamentos que están por detrás de las decisiones judiciales ${ }^{71}$. En ese sentido, tal doctrina revive (es cierto que en nueva perspectiva) la teoría declaratoria -que se opone a la teoría constitutiva en la que el juez crea derecho-, sustentando que, incluso cuando ninguna regla regula el caso, la decisión "descubre" el derecho.

En realidad, las decisiones que afirman principios o derechos fundamentales pueden ser vistas como constructivistas o interpretativistas, dependiendo del lugar de donde se parte para analizarlas. Ahora, al partirse de la premisa de que no se pueden tomar en cuenta los principios para afirmar un derecho no expresado, la decisión que así lo hiciera, lógicamente, será vista como creadora del derecho, pero, al admitirse que el juez debe considerar principios y concretizar derechos, la decisión será comprendida como interpretativa. En ese caso, es imprescindible un sistema de precedentes.

\section{LA APROXIMACIÓN ENTRE LOS SISTEMAS DEL CIVIL LAW Y DEL COMMON LAW Y LA IMPRESCINDIBILIDAD DEL RESPETO A LOS PRECEDENTES}

Este texto se propuso demostrar, a través de un método histórico-crítico, la aproximación entre las jurisdicciones del civil law y del common law y sólo a partir de ahí, la necesidad del respeto a los precedentes en el sistema del civil law. No hubo intención en profundizar los fundamentos -que son varios- para justificar el respeto a las decisiones judiciales, ni mucho menos algún interés en tratar de aspectos técnicos relativos a la metodología del empleo de los precedentes.

Aunque los precedentes hayan sido fundamentados para el desarrollo del common law, el stare decisis tiene sustentación especialmente en la igualdad y en la previsibilidad. El stare decisis no se confunde con el common law, habiendo surgido en el curso de su desarrollo.

71 DWORKIN, Ronald. O império do direito. São Paulo: Martins Fontes 1999, pp. 273-274. 
Es equivocado imaginar que el stare decisis existe porque el juez del common law crea el derecho. Como se verifica en la doctrina de MacCormick, especialmente en Retórica y el Estado de Derecho, en "tiempos recientes, incluso en los países del common law, el derecho jurisprudencial puro es relativamente raro. Mucho del derecho jurisprudencial ahora toma la forma de interpretaciones explicativas (glosses) de la ley"72.

Los precedentes que interpretan leyes o precedentes de la Suprema Corte americana evidencian, por sí mismos, la razón de ser del stare decisis. Recuérdese que, considerando el valor de la seguridad, la doctrina americana demuestra gran preocupación con el overruling y con la fuerza del stare decisis delante del control difuso de constitucionalidad ${ }^{73}$.

A propósito, regresando al argumento de que el stare decisis sólo existe en derivación de la inacción del legislativo, basta constatar que no hay déficit de legislación en los Estados Unidos, no teniendo cabida la suposición de que el precedente tiene fuerza obligatoria por falta de actuación del legislador.

Por otra parte, la tradición del civil law, anclada en las razones de la Revolución Francesa, fue completamente 'des-caracterizada' con el pasar del tiempo. El juez, a quien inicialmente le era prohibido interpretar la ley, pasó a interpretarla de forma paulatina, cayendo en desuso las comisiones legislativas instituidas para resolver las dudas de interpretación y, después, el primer semblante de la Casación, delineada como órgano de naturaleza no jurisdiccional para casar las interpretaciones judiciales incorrectas.

La evolución del civil law es la historia de la superación de una idea instituida para viabilizar la realización de un deseo revolucionario y que por lo tanto, nació con la marca de una utopía. Como dogma, esta noción se mantuvo viva aunque la evolución del civil law le restara características. Recuérdese que la fuerza del constitucionalismo y la actuación judicial mediante la concreción de las reglas abiertas, hizo surgir un modelo de juez completamente distinto del deseado por la tradición del civil law. De modo que el civil law vive actualmente la contradicción entre el juez real y el juez de los libros o de las doctrinas acríticamente preocupadas sólo en justificar que la nueva función del juez cabe dentro del modelo del principio de separación de poderes. En verdad, la doctrina se olvida de esclarecer que el juez de la Revolución Francesa nació casi muerto y que el principio de la estricta separación de los poderes sufrió una mutación con el pasar del tiempo, teniendo, hoy en día, otra figura.

No hay duda que el papel del actual juez del civil law y especialmente el del juez brasilero a quien le es encargado el poder-deber de controlar la constitucionalidad

\footnotetext{
${ }_{72}$ MACCORMICK, Neil. Rethoric and the rule of law - A theory of legal reasoning. New York: Oxford University Press, 2005. p. 176.

73 GERHARDT, Michael J. Op. cit.
} 
de la ley en el caso concreto, se aproxima mucho a la función ejercida por el juez del common law, especialmente a la realizada por el juez americano. Sucede que, a pesar de la aproximación de los papeles de los magistrados de ambos sistemas, sólo en el common law se confiere respeto a los precedentes.

La ausencia del respeto a los precedentes está fundada en la falsa suposición, propia del civil law, de que la ley sería suficiente para garantizar la certeza y la seguridad jurídica. Resáltese que esa tradición insistió en la tesis de que la seguridad jurídica sólo sería viable si la ley fuese estrictamente aplicada. La seguridad sería garantizada mediante la certeza advenida de la subordinación del juez a la ley. No obstante, es interesante percibir que la certeza jurídica adquirió aspectos antagónicos en el civil law y en el common law. En el common law se fundamentó el stare decisis, mientras que en el civil law fue utilizado para negar la importancia de los tribunales y de las decisiones.

Sin embargo, cuando se "descubrió" que la ley es interpretada de diversas formas y, visiblemente, que los jueces del civil law rutinariamente deciden de diferente forma los "casos iguales", curiosamente no se abandonó la suposición de que la ley es suficiente para garantizar la seguridad jurídica. Ahora, al ser innegable que la ley es interpretada de diversas formas, haciendo surgir distintas decisiones para los casos iguales, debería haber surgido, al menos en sede doctrinaria, la lógica e innegable conclusión de que la seguridad jurídica sólo puede ser garantizada marcándose la igualdad ante las decisiones judiciales y, de tal forma, estableciéndose el deber judicial de respeto a los precedentes. Al final, la ley adquiere mayor significación cuando bajo amenaza de violación o después de haber sido violada, de forma que la decisión judicial que la interpreta no puede quedar en segundo plano o desmerecer cualquier respeto al Poder que la pronunció.

La seguridad jurídica, postulada en la tradición del civil law por la estricta aplicación de la ley, está a exigir el sistema de precedentes, establecido hace mucho para asegurar esa misma seguridad en el ambiente del common law, en el que la posibilidad de decisiones diferentes para casos iguales nunca fue desconsiderada y, exactamente por eso, hizo surgir el principio inspirador del stare decisis, mediante el cual los casos similares deben ser tratados del mismo modo (treat alike cases).

Aunque debe ser el mínimo indeseable, para un Estado democrático, dar decisiones desiguales a los casos iguales, extrañamente no hay alguna reacción en la doctrina y en la praxis. Es como que si estas decisiones no fuesen vistas o fuesen admitidas por ser inevitables. La advertencia de que la ley es igual para todos, que siempre se vio escrita sobre la cabeza de los jueces en las salas del civil law, además de no bastar más, constituye una broma de mal gusto a aquel que, en una de las salas del Tribunal y bajo tal inscripción, recibe una decisión distinta de la proferida -en un caso idéntico- por la Cámara, cuya sala se localiza a unos metros de allí, en el mismo largo e indiferente corredor del predio que, antes de todo, debería abrigar la igualdad de tratamiento ante la ley. 